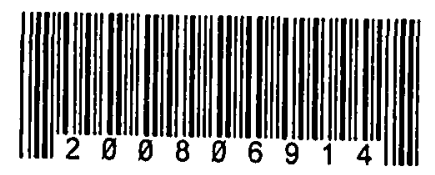

\title{
DEFINING AND MANAGING ENVIRONMENTAL FLOWS: INPUTS FROM SOCIETY
}

\author{
by
}

\begin{abstract}
JEFF BENNETT*
Two key questions regarding the management of Australia's riverine environments are addressed: how much water should be allocated for environmental flows; and how should water entitlements for environmental flows be acquired and managed. First. an application of the choice modelling technique in the context of River Red Gum forests along the River Murray is used to demonstrate how the marginal values of water for the environment can be estimated for comparison against prices paid by extractive users of water. Second, mechanisms in the public and private sectors for the purchase of environmental water are contrasted.
\end{abstract}

Key words: Environmental flows; Non market valuation; Choice modelling, Water trusts

JEL Codes: D61, H44, L31, Q51

\section{Background}

A key driver of the water reform process that has engaged Australians over the last two decades has been the deterioration of the environmental condition of river systems across the country. The threat of extinction for the iconic Murray Cod, closures of the mouth of the River Murray, blue-green algal outbreaks in the Darling River, shrinkage of the Ramsar-listed Macquarie Marshes, the death of River Red Gum Forests along the Murray and a compromised Snowy River were all perceived by conservationists and a high proportion of the general public as indicative of widespread mismanagement of the nation's water resources.

The waters in many of the nation's river systems were over-allocated to extractive uses. For over a century, governments had responded to the vested interests of extractive users by allocating water entitlements to the point where, particularly in the Murray-

- Property and Environment Research Center (PERC) Bozeman, Montana, USA, and Craw ford School of Economics and Government, Australian National University. The assistance of Robert Dumsday, Robert Gillespie, Marit Kragl, Chris Lloyd, Simon Ransome and Maria Lille in the development of the material presented in this paper is gratefully acknowledged. Errors remain the responsibility of the author:

167

(C) 2008. THE ECONOMIC SOCIETY OF AUSTRALIA. ISSN 0812-0439 


\section{JEFF BENNETT}

Darling Basin, the extent of the combined entitlements were in excess of the available supply. Hence, an entitlement to one mega-litre (ML), even in the wettest of years, could only provide access to a fraction of that volume. Flows to protect the environmental condition of the rivers were minimal and readily abandoned in dry years when the threat to irrigated crops was at its greatest.

The response to growing public concerns over the shrinking supply of environmental amenity from rivers-along with a redistribution of political power away from rural areas to marginal urban electorates with heightened environmental awareness -has in part precipitated two decades of water reform. As well as being focused on improving the efficiency of water use in irrigation, the reform process has targeted the development and implementation of 'water sharing plans' that specifically allocate water for 'environmental flows'. Best known of the actions taken in this regard was the establishment of a 'cap' on extractions from the Murray-Darling Basin system. Right across the rivers of Australia, decisions have been made, and continue to be made, that make a trade-off between the use of water for extractive purposes and for environmental protection.

Two key questions emerge in making the trade-off. The first involves an assessment of the demands for water: what are the relative marginal values of water in its competing uses? This question should be addressed in order to assess the merits of allocating water away from, say, irrigating a wheat crop so that it can be used to inundate a wetland and thereby promote a bird breeding event. Inequality across those marginal values indicates the potential for gains from re-allocation. The second question focuses on the management of water: once environmental flow allocations have been determined, how will they be acquired and then managed?

Only limited economic analysis has been conducted to address these questions. With regard to the demand-assessment question, emphasis has been given to inputs from the bio-physical sciences. For instance, the water-sharing plans developed in NSW were predominantly structured around assessments of the current environmental condition of rivers. Rivers in poor ecological condition were viewed as meriting additional flows, particularly if the current economic conditions of the agricultural enterprises in the river valleys were robust. So whilst a trade-off of sorts was considered, the plans primarily missed the point that assessments should be conducted 'at the margin' and in terms of the values generated by the competing uses. Hence, the consideration of additional value that society would enjoy from more water being allocated as environmental flow and reduction in value that society would endure because water was taken away from irrigated agriculture was not made.

In other cases, the trade-off appeared to be based more on political imperative than analytical process. For instance the allocation of environmental flows under the "Living Murray' initiative pre-empted the conclusion of research work aimed at developing an ecological and economic appreciation of the impacts of numerous possible management changes. The Living Murray flows were specifically earmarked for the protection of high profile 'iconic' sites along the river, such as the Barmah-Millawah Forest and the Hattah Lakes.

In terms of the question of how environmental flows are to be acquired and managed, this has largely been presumed the province of the State Government agencies with natural resource management responsibilities. Where excessive extractive entitlements have been issued, governments have sought infrastructure investments that 
will reduce delivery losses so that the water so recovered can be designated as environmental flows. Similarly, irrigators have been assisted financially by governments to increase their water-use efficiency in order to release water for the environment. Where such opportunities have been exhausted, some governments have entered water markets as buyers. Private sector entities have also been established to buy water, some on a trial basis and others more formally.

The contribution made by this paper is in the development of a better understanding of the answers to both of these questions. In terms of defining the demand side, the use of stated preference, non-market valuation techniques in providing an improved appreciation of the extent of the marginal values held by the community for increased environmental flows is demonstrated. The context of the demonstration is the development of policy to protect the River Red Gum forests along the River Murray. The paper includes the results of a choice modelling study aimed at estimating the community's value of the continued survival of these remnant forests.

The second contribution-on the management aspect-is made through a review of the operations of private-sector entities established to purchase and manage environmental flows. Comparisons are made with the experiences of similar entities in the western states of the United States of America. A key observation is that the question of who acquires and manages the water can have direct impacts on the choice of how the water is allocated.

\section{The River Red Gums of the Murray: A Choice Modelling Application}

A reduced incidence of flooding, primarily due to water extraction for irrigation, has left the River Red Gum (RRG) forests along the Murray River in a depleted and degraded state. Timber harvesting and cattle grazing in the forests have also had adverse impacts on their health (VEAC, 2006). Numerous policy initiatives have been taken to redress the declining state of the forests including the Living Murray initiative at the Commonwealth level. The Victorian Government asked the Victorian Environment Assessment Council (VEAC) to undertake an Investigation into the River Red Gum Forests of the River Murray and its Victorian tributaries in 2005.' As an input into that inquiry a Benefit Cost Analysis (BCA) was commissioned to assess the marginal benefits and marginal costs of moving to a range of alternative RRG management options, including the provision of environmental flows. To enable such a BCA to be performed, estimates of the marginal values associated with improved RRG condition were required. Because these are largely non-marketed, non-use environmental values, a stated preference method, Choice Modelling (CM), was selected for application, given its capacity to provide value estimates for a range of management scenarios from one data collection exercise (Bennett and Blamey, 2002).

In brief, the CM technique involves a sample of people being asked to make a sequence of choices between resource management strategies. Each strategy is described in terms of its impacts on a range of environmental attributes and its cost to the respondent. From their choices, it is possible to infer the values that respondents

The draft findings of the Investigation along with various commissioned reponts can be found at: http://www.veac.vic.gov.at/riverredgum.htm. The specific report containing details of the $C M$ application outlined in this paper is available at: http://www.veac.vic.gov.alu/eedea.htm. 


\section{JEFF BENNETT}

place on the various environmental attributes. The technique's flexibility in application enables it to be adapted to the specifics of the decision-making context at hand. Its development over the past ten years has shown it to be a robust and reliable tool for natural resource management (Adamowicz, 2006).

Designing the $\mathrm{CM}$ application for the RRG case involved several stages. The first was to define the set of attributes used to describe the benefits derived from forests and delineate the ranges of values those attributes could take given the types of management scenarios under consideration. This required that the views of forest managers and scientists (who 'supply' the attributes) and the views of the communities (who 'demand' the attributes) be considered.

Experts from Deakin University, the Arthur Rylah Institute, the Victorian Department of Sustainability and Environment, VEAC staff, and land managers were consulted in the 'supply-side' process of attribute definition. The purpose of these consultations was to decide the short-list of forest attributes that best represent the land management and scientific perspective. On the 'demand-side', the forest attributes were refined through a sequence of focus groups designed to reflect the appreciation of forest values and understanding of forest issues held by members of the general public. Focusgroup meetings each involving about ten participants were held in Melbourne, Echuca, and Bairnsdale. The attributes that were selected, together with their levels, are shown in Table 1. While the upper and lower levels for each environmental attribute were set with reference to expert opinion and a planning horizon of twenty years, the intermediate levels were established to provide coverage across the range.

TABLE 1

ATTRIBUTES AND THEIR LEVELS

\begin{tabular}{lll}
\hline \multicolumn{1}{c}{ Attribute } & \multicolumn{1}{c}{ Description } & \multicolumn{1}{c}{ Levels } \\
\hline Cost & Compulsory annual payment $(\$)$ & $0 ; 20 ; 50 ; 100$ \\
Healthy RRGs & Area (hectares) & 54,$000 ; 67,000 ; 74,000 ;$ \\
& & 80,000 \\
Threatened Parrots & Number of breeding pairs & $900 ; 1,200 ; 1,500 ; 1.800$ \\
$\begin{array}{l}\text { Murray Cod and other } \\
\text { threatened native fish }\end{array}$ & Percentage of pre-European numbers & $10 ; 20 ; 40 ; 60$ \\
Recreation Facilities & Number of campsites with facilities & $6 ; 9 ; 12 ; 18$ \\
\hline
\end{tabular}

The next stage-questionnaire development-included the determination of an appropriate context or frame for the questioning, a statement of the relevant forest issues, potential strategies to deal with the forest issues, an appropriate payment vehicle, and a range of matters relating to the presentation of the questionnaires and the information embedded therein. Much of this development was informed by potential respondents' attitudes and capacities as collected during the focus groups.

The survey material so derived included a questionnaire booklet and background information about the forest areas in the form of a separate full-colour information poster which contained a map of the study area. The booklet set out questions relating to respondents' attitudes towards, and uses of, the forests; explanations of the issues and trade-offs in their use; ways in which management might be improved; why people should have to pay for improving forest health; how they might do this and what could be achieved; the choice sets; debrieling questions; and questions to establish the socio- 
economic characteristics of respondents. The questionnaire had five versions with different choice sets to accommodate the experimental design that ensured adequate coverage of all the possible combinations of attribute levels.

To facilitate the extrapolation of survey results across all of the Victorian population, sub-samples of respondents were selected from within the Murray River region where the forests are located ('in-region') and from two 'out-of-region' samples (Melbourne and Bairnsdale) to detect relationships between respondents' distance from the site in question and the values held (van Bueren and Bennett, 2004; Rolfe and Bennett, 2006).

The 'drop off/pick up' (DOPU) method of questionnaire distribution was used with the option of a mail back. Sampling of households was random from a geographically stratified sample of streets. Lions Clubs and Landcare groups were contracted to carry out the survey in November 2006.

A total of 983 questionnaires were collected with 487 respondents from the inregion sub-samples, 257 in the outside-region urban sub-sample (Melbourne) and 239 in the rural outside-region sub-sample (Bairnsdale). Comparisons between sample characteristics and 2001 ABS census data revealed that the sample population was slightly older, more likely to be male, better educated and with higher average incomes.

Three choice models were estimated for each sub-sample: one that involved only the choice attributes as explanatory variables modelled using the 'conditional logit' formulation; and a second that also incorporated significant socio-economic and attitudinal variables ('full model'). The latter ('full model') was also modelled using 'nested logit'.

Under the 'conditional logit' model, the probability of a respondent choosing one of the options in the choice sets is modelled as a function of the attribute levels and the respondent's socio-economic characteristics. The expectation is, therefore, that the probability of a respondent choosing an option will increase as that option provides more of the desirable environmental outcomes and will also increase with socioeconomic characteristics such as more education and income. The probability is thus an indication of the relative wellbeing that respondents enjoy from the options, assuming that respondents will choose the options that provide them with the highest levels of wellbeing. Hence, wellbeing (U) is modelled as:

$$
\mathrm{U}=\mathrm{u}(\mathrm{An}, \mathrm{Sm})
$$

where $\mathbf{u}$ describes the functional form of the relationship;

An is the level of the $\mathrm{n}^{\text {th }}$ attribute of the choice options; and

$\mathrm{Sm}$ is the measure of the $\mathrm{m}^{\text {th }}$ socio-economic characteristic of the respondent.

The 'conditional logit' model requires a specific formulation of the distribution of the errors remaining after the impacts of the attribute variables have been taken into account. This distribution requires that the inclusion of choice alternatives that are irrelevant to the choice process has no impact on choice behaviour. This is known as the 'Independence of Irrelevant Alternatives' or IIA assumption. Tests performed on the 'conditional logit' models showed that the IIA assumption was breached. To ensure the validity of the results, an alternative modelling process-known as 'nested logit' - was used in the development of the models that related wellbeing to both attribute levels and socio-economic characteristics. Under the 'nested logit' model, respondents are assumed to make choices regarding the preferred options using a two-stage process. 


\section{JEFF BENNETT}

First, respondents decide between options involving a change in resource management and the one that does not. In the model, this choice is explained by the socio-economic characteristics of respondents $(\mathrm{Sn})$. Second, those respondents who decide on a change make a choice between the two alternatives involving a change in resource use. The modelling of this level of the choice involves wellbeing as a function of the attributes (An). Because the 'nested logit' modelling process establishes two branches in the decision making 'tree', it avoids the problem of IIA violations that compromise the 'conditional logit' models.

TABLE 2

CHOICE MODELLING VARIABLES

\begin{tabular}{ll}
\hline Variable code & Description \\
\hline ASC & Alternative Specific Constant \\
Costs & Cost of choice alternative ( $\$$ pa over 20 years) \\
Healthy RRG & Area of healthy River Red Gum forests protected ('000 ha) \\
Parrots & Breeding pairs of threatened parrots ('00 pairs) \\
Cod & Percentage of pre-European populations of Murray Cod and other \\
& threatened native fish (\%) \\
Recreation & Recreation facilities (no. of campsites with facilities) \\
asc & Alternative specific constant \\
ageasc & Respondent age $\times$ asc \\
eduasc & Respondent educational status $\times$ asc \\
incasc & Respondent household income $(\$ 000) \times$ asc \\
genasc & Respondent gender $(1=$ male $) \times$ asc \\
kidsasc & Kids $(1=$ with) $\times$ asc \\
noageasc & Refusal to provide age $(=1) \times$ asc \\
noeduasc & Refusal to provide educational status $(=1) \times$ asc \\
noincasc & Refusal to provide income $(=1) \times$ asc \\
visasc & Visited the forests $(=1) \times$ asc \\
underasc & Understood the questions $(=1) \times$ asc \\
confasc & Confused by the questions $(=1) \times$ asc \\
greenasc & Environmental affiliation $(=1) \times$ asc \\
farmasc & Agricultural affiliation $(=1) \times$ asc \\
fishasc & Fished in the Murray $(=1) \times$ asc \\
walkasc & Walked in the forests $(=1) \times$ asc \\
swimasc & Swam in the Murray $(=1) \times$ asc \\
IV & Inclusive value for the nesting structure \\
\hline
\end{tabular}

The An and Sm variables for which data were collected in the survey and then used to model respondent wellbeing are set out in Table 2. Both modelling approaches involve the incorporation of 'Alternative Specific Constants' (ASC's). In the 'conditional logit' model, the ASC is set equal to one for the choice alternatives that involve a change in resource use. In the 'nested logit' model, an ASC is established for each step of the choice process. In both cases, the role of the ASC is to account for any variation in wellbeing across respondents that is not explained by the attributes (An) and the socio-economic characteristics ( $\mathrm{Sm}$ ). In effect, it acts as a 'residual' explanatory variable. Importantly, the ASC is also used to interact with the socio-economic characteristic variables. Hence the $\mathrm{Sm}$ variables appear in the models as interactions 
with the ASC (e.g., 'ageasc' is the multiplicand of respondent age and the ASC). This avoids technical problems associated with the mathematical routines used to estimate the models.

Of the total of 983 respondents, 98 did not answer the question relating to income. Rather than dropping these respondents from the analysis, their income was taken to be the average value of all respondents who had provided an answer. A dummy variable was included to account for any systematic differences between respondents who did not reveal their income and those who did. The same strategy was followed for the respondents who did not answer the education and the age questions.

The results displayed in Table 3 are the estimates of the coefficients of the An and $\mathrm{Sm}$ variables in the choice modelling equations for the attribute only model and the full model under 'nested logit'. While the signs of the coefficients indicate the direction of the relationship between the variable and the wellbeing of the respondent, their magnitudes have no specific interpretation. Their magnitudes are only interpretable when they are considered relative to each other. In that context, they can be interpreted as a measure of the relative importance of two attributes: i.e. how much of an attribute is a respondent willing to give up in order to receive more of another and remain equally well-off. These are the attributes' implicit prices.

The estimates of the socio-economic variables' coefficients require special interpretation because of their interaction with the ASC. Hence, a positive coefficient estimate for the 'in-casc' variable means that respondents with higher incomes are more likely to choose resource management options that involve improved environmental outcomes.

The validity of the models can be assessed in a number of ways. First, their ability to explain choice behaviour is reflected by the significance and signs of the coefficients estimated for the independent or explanatory variables. For instance, the cost attribute would be expected a priori to be negatively signed and significant. Similarly, the environmental 'goods' being offered by change options would be anticipated to have positive signed coefficients and be significant. Other expectations relate to the socioeconomic variables. Positive signs would be expected for characteristics such as income and education. Second, models can be assessed with reference to their statistical power in predicting respondents' choices. The pseudo $\mathrm{R}^{2}$ statistic gives some information on this strength for the 'conditional logit' models with models of acceptable strength being scored between 0.15 and 0.40 . The log likelihood score supplements the pseudo $R^{2}$ with lower log likelihood scores being evidence of superior models.

Hence from Table 3, the Attribute-only model for the Melbourne sub-sample has a relatively weak pseudo $\mathrm{R}^{2}$ but very strong levels of significance for the attribute coefficients, with the a priori expected signs. The improvement in model performance achieved though the incorporation of the socio-economic variables (Full-nested) is demonstrated by the fall in the log likelihood score from -1187 to -992 . Note that the size and sign of the ASC varies between the Attributes-only and full-nested models because the incorporation of the socio-economic variables takes away some of the 'residual explanatory' function of the ASC in the attributes only model.

The 'Cost', 'Parrots', and 'Cod' attributes were found to be highly significant in all sub-samples with the expected signs. 'Healthy RRGs' is significant and positive in the Melbourne and Bairnsdale sub-samples. The results from Table 3 indicate that reducing the costs, increasing the area of healthy RRG forests, increasing the nunber of 


\section{JEFF BENNETT}

threatened parrot pairs, or increasing the percentage of pre-European populations of Murray Cod and other threatened native fish will increase the probability of people selecting a specific choice alternative. Hence higher levels of these environmental attributes are associated with higher levels of respondent wellbeing.

TABLE 3

RED RIVER GUM CHOICE MODELS

\begin{tabular}{|c|c|c|c|c|c|c|}
\hline & Melbourne & & Bairnsdale & & In-region & \\
\hline Variable & Attrib & Nested & Attrib & Nested & Attrib & Nested \\
\hline $\mathrm{ASC}$ & $0.47^{*}$ & $-0.38 * * *$ & $-0.97^{* * *}$ & $-0.56^{* * * *}$ & $0.56^{* * *}$ & $-0.34^{* * *}$ \\
\hline Costs & $-0.07 * * *$ & $-0.02 * * *$ & $-0.01 * * *$ & $-0.01 * * *$ & $-0.01 * * *$ & $-0.02 * * *$ \\
\hline Healthy RRGs & $0.02 *$ & $0.03^{* * *}$ & $0.03 * * *$ & $0.03 * * *$ & -0.00 & 0.00 \\
\hline Parrots & $0.08 * * *$ & $0.10^{\text {***** }}$ & $0.05 * * *$ & $0.09 * * *$ & $0.04 * * *$ & $0.06^{* * * *}$ \\
\hline Cod & $0.02 * * *$ & $0.02 * * *$ & $0.01^{* * *}$ & $0.01 * * *$ & $0.01 * * *$ & $0.02 * * *$ \\
\hline Recreation & -0.01 & 0.00 & -0.01 & -0.01 & -0.00 & -0.00 \\
\hline Asc & & -0.81 & & 0.39 & & -0.70 \\
\hline Ageasc & & -0.00 & & -0.01 & & 0.00 \\
\hline Eduasc & & $0.11 * * *$ & & -0.05 & & $0.11 * * *$ \\
\hline Incasc & & $0.01^{* *}$ & & $0.01^{* * *}$ & & $0.01 * * *$ \\
\hline Genasc & & $0.33^{* * * *}$ & & 0.26 & & $-0.22^{*}$ \\
\hline Kidsasc & & -0.26 & & 0.07 & & $-0.46^{* *}$ \\
\hline Noageasc & & 0.08 & & & & \\
\hline Noeduasc & & 23.05 & & $-2.05^{* * *}$ & & $0.81^{*}$ \\
\hline Noincasc & & $-0.47 * *$ & & $-1.02 * * *$ & & $-0.79 * * *$ \\
\hline Visasc & & 0.14 & & $0.70^{* * *}$ & & $0.15^{* * *}$ \\
\hline Underasc & & $1.14^{* * *}$ & & $1.12^{* * *}$ & & $0.59 * * *$ \\
\hline Confasc & & $-0.42 * * *$ & & $-0.30 * * *$ & & $-0.28 * * *$ \\
\hline Greenasc & & $0.64^{* *}$ & & $0.54^{* *}$ & & $0.31^{* * *}$ \\
\hline Farmasc & & 0.06 & & 0.09 & & $-0.31^{* * *}$ \\
\hline Fishasc & & $-0.93^{* * *}$ & & $-1.47 * * *$ & & \\
\hline Walkasc & & $0.49 * *$ & & & & $0.29 *$ \\
\hline Swimasc & & $0.82 * *$ & & & & \\
\hline Birdasc & & & & & & $0.42 * *$ \\
\hline IV & & $0.44^{* * * * *}$ & & 0.305 & & $0.32 * *$ \\
\hline Choice Obs & 3735 & 3435 & 3210 & 2814 & 6837 & 6162 \\
\hline Pseudo $\mathrm{R}^{2}$ & 0.132 & & 0.023 & & 0.0615 & \\
\hline Log likelihood & -1187 & -992 & -1159 & -861 & -2349 & -1953 \\
\hline Restricted LL & & -1114 & & -897 & & -2143 \\
\hline
\end{tabular}

Notes: $\quad$ Significance levels indicated by: ${ }^{*} 0.1,{ }^{* *} 0.05,{ }^{* * *} 0.01$.

Coefficient estimates rounded to two decimal places.

Most of the significant socio-economic variables have the expected signs. 'Income', 'visitation', and 'education' are predominantly positive, as is the understanding of the information provided on the survey poster. Accordingly, higher levels of these variables are associated with respondents choosing alternatives that involve environmental improvements.

The 'confusion' variable is negative and significant, indicating that respondents who were confused by the choice questions were more likely to choose the status quo alternative over other forest management alternatives, despite their improved 


\section{DEFINING AND MANAGING ENVIRONMENTAL FLOWS}

environmental outcomes. A consistent result across the sub-samples was that respondents who did not reveal their income were less likely to support changes in forest management. As expected, respondents who were members of an environmental organisation were likely to support changing forest management, and respondents who were associated with agricultural industry in the 'within region' sample preferred the current situation. Respondents associated with the timber industry did not have a statistically significant effect in the models, probably because of their small representation in the samples.

Different outdoor activities in the Murray River Red Gum forests were significant between sub-samples. While bushwalking is positive and significant in the Melboume and 'within region' sub samples, bird-watching is positive only in the 'within region' sub-sample. The fishing variable is negative and significant in the Melbourne and Bairnsdale sub-samples, indicating that recreational fishers would prefer no change, contrasting with the significant overall support from those sub-samples for increasing the populations of threatened native fish.

The estimated attribute coefficients have been used to estimate the marginal values of Healthy RRGs, Parrots, Cod, and Recreation. These 'implicit prices' are the marginal willingness to pay for the average respondent household over a twenty-year period for a unit increase in the attribute and are calculated by dividing the estimated coefficient for the attribute (from the 'full model') by the estimated coefficient for the cost attribute.

The results in Table 4 show that respondents in the Bairnsdale and Melbourne subsamples are willing to pay $\$ 3.29$ and $\$ 1.45$ respectively for a 1,000 hectare increase in the area of healthy River Red Gum forest (per annum per household for twenty years). Within-region respondents recorded a low positive implicit price for increasing the area of healthy forest that was not significantly different from zero. Respondents were found to attach a positive value to increasing the numbers of breeding pairs of threatened parrots, ranging from around $\$ 4$ to $\$ 8.40$ per 100 pairs (per household per annum for twenty years). The implicit price for a $1 \%$ increase in the populations of Murray Cod and other threatened native fish species varies across the sub samples from about $\$ 1.00$ to $\$ 1.40$ per annum per household over twenty years. Implicit prices for the recreation attribute are not significant for any of the sub samples.

TABLE 4

IMPLICIT PRICE ESTIMATES

\begin{tabular}{lccc}
\hline $\begin{array}{l}\text { Sub sample } \rightarrow \\
\text { Attribute } \downarrow\end{array}$ & $\begin{array}{c}\text { Melbourne } \\
(\$ / \mathrm{yr} / \mathrm{hh})\end{array}$ & $\begin{array}{c}\text { Bairnsdale } \\
(\$ / \mathrm{yr} / \mathrm{hh})\end{array}$ & $\begin{array}{c}\text { Within region } \\
(\$ / \mathrm{yr} / \mathrm{hh})\end{array}$ \\
\hline Healthy RRGs/1,000 ha & $1.45^{* * *}$ & $3.29^{* * *}$ & 0.0677 \\
& $(0.46)$ & $(1.29)$ & $(0.47)$ \\
Parrots/100 pairs & $4.39^{* * * *}$ & $8.39^{* * * *}$ & $3.96^{* * * *}$ \\
& $(1.04)$ & $(2.76)$ & $(1.04)$ \\
Cod/1\% increase & $1.02^{* * * *}$ & $1.37^{* * * *}$ & $1.09^{* * *}$ \\
& $(0.17)$ & $(0.44)$ & $(0.17)$ \\
Recreation/campsite & -0.11 & -0.85 & -0.24 \\
& $(0.62)$ & $(1.53)$ & $(0.66)$ \\
\hline Notes: Significance levels indicated by: ${ }^{*} 0.1,{ }^{* *} 0.05,^{* * *} 0.01$ & \\
Standard Errors in parentheses. & & &
\end{tabular}


The implicit prices estimated from the CM data are directly applicable to the consideration of alternative forest management options, including watering regimes. Specifically, they are compatible, as welfare change measures, with the principles of Benefit Cost Analysis (BCA). The process of employing implicit prices in BCAs involves four basic stages: ${ }^{2}$

1. Predicting the impact of a management change on the attributes used in the choice modelling exercise relative to the predicted continuation of the status guo.

2. Multiplying the implicit prices by the respective predicted attribute change to estimate the per-respondent household willingness to pay for each attribute change.

3. Aggregating the per-respondent household willingness to pay across all attribute changes.

4. Extrapolating across the relevant population, using the survey response rate, to estimate the societal willingness to pay for the management change.

This process was used to estimate values associated with three management scenarios that include different environmental flows, all relative to a base case:

Scenario I BASE CASE- No new management changes over the next twenty years (but including $500 \mathrm{GL}$ [giga-litres] per anmum under the Living Murray Initiative and $127 \mathrm{GL}$ for existing annual environmental allocations)

Scenario 2 All VEAC's proposed recommendations including new national parks but with no additional water

Scenario 3 All VEAC's proposed recommendations including national parks but with $2,000 \mathrm{GL}$ additional water every five years on average

Scenario 4 All VEAC's proposed recommendations including national parks and VEAC's estimated 4,000 GL additional water every five years on average

The outcomes in terms of the significant attributes were developed by VEAC and are summarised in Table 5 .

TABLE 5

PROJECTED ENVIRONMENTAL OUTCOMES

\begin{tabular}{lrrrr}
\hline & Scenario 1 & Scenario 2 & Scenario 3 & Scenario 4 \\
\hline Healthy RRGs ('000 ha) & 54 & 60 & 65 & 80 \\
Threatened parrots ('00 pairs) & 9 & 10 & 14 & 16 \\
Murray Cod and other & 10 & 10 & 20 & 30 \\
threatened native lish (\% & & & & \\
increase) & & & & \\
\hline
\end{tabular}

Demographic data (approximate for 2006) and survey response rates relevant to estimating the environmental values are summarised in the table below.

2 These stages can he made more sophisticated through the recognition of divergences between the survey respondent characteristics and those of the population and the prospect of survey mon-respondents hivving positive villues for altribute impacts. 
DEFINING AND MANAGING ENVIRONMENTAL FLOWS

TABLE 6

DEMOGRAPHIC DATA

\begin{tabular}{lcc}
\hline & Number of households (m) & Survey response rate \\
\hline Melbourne & 1.3 & 50 \\
Within region & 0.1 & 80 \\
Out of region & 0.3 & 70 \\
\hline
\end{tabular}

The per cummum (р.a.) values (over twenty years) across the Victorian population for the three change scenarios are therefore:

Scenario 2: $\quad \$ 14,732,600$

Scenario 3: $\quad \$ 53,007,400$

Scenario 4: $\quad \$ 97,751,800$

To extract the marginal value of environmental flows for the RRG, it is necessary to reassign Scenario 2 as the base case because it involves no additional water allocations to the forests. Hence, the impacts of environmental flows on the RRG values are:

Scenario $3(2,000 \mathrm{GL}$ every five years or $400,000 \mathrm{ML}$ p.a. on average): $\$ 38,274,800$ or $\$ 96$ per $M L$ pa on average

Scenario $4(4,000 \mathrm{GL}$ every five years or $800,000 \mathrm{ML}$ p.a. on average): $\$ 83,019,200$ or $\$ 104$ per ML p.a. on average

At a discount rate of five per cent, this annual value for twenty years is worth around $\$ 1,200$ per $\mathrm{ML}$ in present value terms. In other words, the people of Victoria are willing to pay up to $\$ 1,200$ per $M L$ to see the sort of environmental improvements to the RRG forests that have been forecast by VEAC to result from increased watering.

The first point to note regarding this estimate is that it is well within the price range being paid for irrigation water. In other words, the people of Victoria value the health of the RRG forests of the Murray to be competitive in bidding for entitlement against the extractive competition. This finding does not incorporate any 'spill-overs' created by the additional environmental flows. Importantly, the riverine environments in NSW and SA would also be improved and extrapolating the findings from this study to the people of those two states would significantly enhance the extent of the environimental 'bid' to an order of magnitude that would prevail against current extractive bids. However, just how competitive the 'environment bid' would be depends in part on supply conditions. With such a significant increase in demand for environmental water as VEAC recommends and with a positively sloped supply function for water, it could be expected that prices of water would increase. To put into perspective the extent of the increase in demand the VEAC recommended flows represent, the average annual total inflows to the Murray River are in the order of $11,200 \mathrm{GL}$.

\section{Managing Environmental Flows}

The question of how strong the environmental flow bid is relative to the extractive uses' marginal values raises the issue of how the environmental flow bid will be expressed in water markets. The presumption of the valuation study reported in this paper, and others like it undertaken in different contexts, is that governments will act on behalf of society to ensure water allocations that reflect the relative marginal values. Indeed a key role to be played by non-market environmental valuation studies is to provide the information 


\section{JEFF BENNETT}

necessary for governments to act in the best interests of society as a whole and to ensure that vested interest groups do not capture the decision making process.

However, the relatively recent emergence of private sector, not-for-profit buyers of water for environmental purposes calls into question the respective roles of the private and public sectors, particularly in an institutional setting where more clearly defined and strongly defended property rights over water have allowed the development of active water markets.

A key element of the water reform process launched by the Council of Australian Governments (COAG) in 1994 and further strengthened in 2004 under the National Water Initiative ${ }^{3}$ was the development of the institutions necessary for the establishment of robust markets for water. Most significantly, water entitlements were separated from property rights over land and State Governments instituted processes for the registration of water title. An emphasis in policy was placed on the importance of markets in securing water-use efficiency. While the primary role of markets was seen as ensuring water was reallocated to its highest marginal value use, within the bounds for extraction established by water sharing plans, their influence has extended into the environmental flow arena.

The clarification of property right definition meant that any over-allocation of water became readily apparent. Establishing any environmental flows in such circumstances, required the reallocation of water away from existing holders of extractive use entitlements. Negotiation between governmental agencies and extractive users in establishing water-sharing plans have secured some voluntary reductions in extractive demands but this has not always secured levels of environmental flows deemed acceptable by governments. The confiscation of rights has proven distasteful to governments at both State and Federal levels and after opportunities for public-sector investments in 'water saving' initiatives, such as more efficient delivery systems both on and off-farm, have been exhausted, purchase by the State on the open market has been ventured.

To put this policy into effect, specific governmental entities have been created. For instance, in NSW RiverBank ${ }^{4}$ has been developed as the means for the State Government to enter water markets. RiverBank has a budget of $\$ 105 \mathrm{~m}$ to be spent over five years to 2011 in open-market transactions to buy entitlements from willing sellers so that title can be converted to environmental flows above levels set by water-sharing plans. Targets are the wetland areas on the Gwydir, Lachlan, Narran, Macquarie and Lower Murrumbidgee Rivers. Funding for RiverBank comes from the State Government's NSW Environment Trust, which in turn is funded from the NSW Waste and Environment Fund. To November 2007, RiverBank had purchased 19.28 GL of general security water, as indicated in Table 7 and an additional $4.7 \mathrm{GL}$ under the Wetland Recovery Programme. The wetlands targeted were the Macquarie Marshes $(4,485 \mathrm{ML})$ and the Gwydir Wetlands $(246 \mathrm{ML})$. In its first financial year of operation (2006-2007), RiverBank spent $\$ 14.4 \mathrm{~m}$ in purchasing $15.6 \mathrm{GL}$, at an average price of $\$ 923$ per ML. Despite these purchase, actual environmental flows delivered through RiverBank have been minimal because the severe drought conditions experienced over

\footnotetext{
http://www.nwe.gov.alu/NWl/index.cfin.

htt|p://www.environment.nsw.gov.au/educalion/nswriverbank.htm.
} 
the year of its operation have meant that general security entitlements have not been supplied.

TABLE 7

RIVERBANK PURCHASES (JUNE 2006 NOVEMBER 2007)

\begin{tabular}{lll}
\hline River & Entitlement Type & Quantity (ML) \\
\hline Gwydir & General security & 2,670 \\
Macquarie & General security & 7,060 \\
Lachlan & General security & 6,550 \\
Murrumbidgee & General security & 3,000 \\
TOTAL & & 19,280 \\
\hline Source: Derek Rutherford and Graeme Enders (RivcrBank), pers. comms., 13 and 16 Dec 2007.
\end{tabular}

In the Federal sphere, the Commonwealth Environmental Water Holder ${ }^{5}$ was established under the Water Act 2007 to hold water entitlements secured either through water saving initiatives or purchases funded by the Australian Federal Government. This particularly pertained to the Murray Darling Basin. The Act was a component of the National Plan for Water Security ${ }^{6}$ under which $\$ 10.05 \mathrm{~b}$ was assigned in order to 'optimise environmental, economic and social outcomes' from a national perspective. A proportion of this fund will be devoted to purchases of water for environmental flows. But purchases are yet to commence under this scheme.

The Living Murray initiative ${ }^{7}$ pre-dates the Water Act, and its plan to secure 500 GL for River Murray 'icon sites' is also being implemented. By October 2007, 100GL of supplementary access entitlements had been acquired in NSW under the Living Murray initiative at a cost of $\$ 20 \mathrm{~m}^{8}$. The relatively low price paid $(\$ 200 / \mathrm{ML})$ reflected the low security entitlement status. A further $20 \mathrm{GL}$ are currently being purchased. The purchasing programme has experienced delays in part because of the abnormally dry conditions experienced over the last five years in the Murray Darling Basin and water has yet to be delivered under the scheme.

In addition, in response to a Commission of Inquiry into the environmental health of the Snowy River, the NSW, Victorian, and Commonwealth Governments formed 'Water for Rivers"' as a public company to secure 212GL of environmental flows for the Snowy River and $70 \mathrm{GL}$ for the River Murray. Funding of $\$ 375 \mathrm{~m}$ was provided by the three governments to form the corporation.

It is informative to note that the National Plan for Water Security makes it explicit that existing State environmental water entitlements sourced either through watersharing plan negotiations or purchases by entities like RiverBank, will be held separately to the Commonwealth's entitlements. With so many different schemes in place to secure environmental flows, questions of coordination have become apparent. The holding and management of entitlements has been further complicated by the entry of private sector not-for-profits both at a local level and more widely.

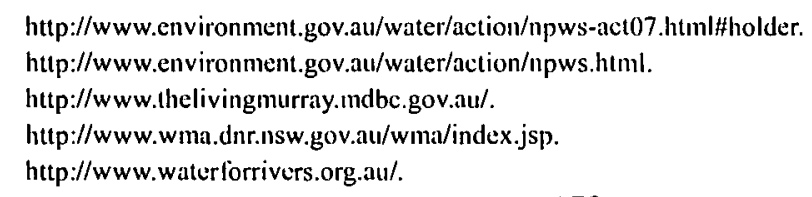




\section{JEFF BENNETT}

An example of a local level initiative is the Waterfind Environment Fund (WEF). ${ }^{10}$ Established alongside its commercial parent, the water trading company, Waterfind Pty Ltd, WEF began operations in 2004 to accept donations of water otherwise destined for extractive use. It is also structured to accept cash donations for the purchase of environmental flows. WEF has also been involved with the Australian Government in the establishment of a computerised environmental water trading system to link in with the South Australian Government's Environmental Water Trust. The Australian Government contribution to this project was $\$ 705,000$, and the target for donations was set at 2.1GL. The modus operandi of WEF is the selection of 'Rescue River Red Gum re-water sites' that they advertise as targets for specific donations, either of water-from irrigators who have water entitlements in excess of their current requirements - or of cash from interested members of the general public. Purchases to date have been small, with current donations amounting to only $\$ 15,000$.

At the wider scale, the NSW Nature Conservation Council (NCC) has recently instituted the Nature Conservation Water Trust (NCWT). " The NCC is an umbrella organisation for 120 conservation groups throughout NSW. The explicit motivation for the formation of the NCWT was the view within the NCC that governmental action to create environmental flows under existing water management regimes was insufficient to support adequately the functioning of wetland systems. In particular, the release for auction by the Queensland Government of eight GL of water from the Warrego River system precipitated the NCC action.

The NCWT has been established as an independent, non-government public trust with four independent directors advised by a scientific advisory panel of four prominent ecologists. Tax deductibility of donations to the NCWT is being sought and the initial work of the scientific advisory panel is being supported by a grant from the NSW Government.

A key difference between the operation of the NCWT and the government purchase schemes is that the Trust will not convert the designation of the entitlements it purchases from extractive to environmental. The trust will therefore use water that is designated as extractive water for environmental purposes. The primary reason for this approach is that the control of water designated as environmental automatically reverts to the government agency with responsibility for water management. The trust would therefore loose control of its asset And, not surprisingly, the NCWT wishes to retain the capacity to manage the use of the water entitlements it purchases. The Trust also wants to avoid passing through the water-use consent process, a requirement when extractive use is changed to environmental flows. This process is both costly and time consuming.

However, the NCWT also wants to make sure that its efforts are not duplicated by government or other initiatives. Recognising the complexities of integrating its operation with those of the NSW Government's RiverBank initiative, the NCWT plans for its scientific advisory panel to work closely with RiverBank staff in determining priorities for flows. In addition, the need for collaboration with the private owners of wetlands to avoid their use of environmental flows for other purposes is also

10) hotp:/www.waterfind.org.au/about.huml.

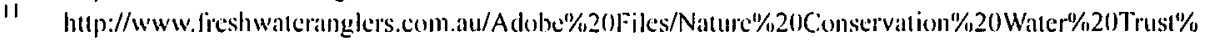
$2025 \% 20$ Sept $\% 202007$.pdf. 
acknowledged. However, no consideration has been given to cooperation with the Commonwealth Environmental Water Holder.

Many of the challenges facing the NCWT have previously been faced by the Water Trusts and other not-for-profits set up in the western states of the United States of America to secure environmental flows. However, Scarborough and Lund (2007), point out that the high costs associated with the purchase of permanent entitlements and their conversion from extractive to environmental purpose have been avoided by leasing entitlements. Of the $71 \mathrm{GL}$ acquired by all parties for environmental flows in the western states between 1998 and 2005, 76\% was leased. Leasing is a practice that has yet to be developed in Australia by either public or private purchasers of environmental flows. This is in contrast to Australian extractive purchasers of entitlements who have shown a preference for leasing. By leasing, the US water trusts retain the flexibility of management sought by the NCWT and have also limited their financial commitments. In addition, they have avoided the time-consuming and costly process of converting the title and have been able to attract entitlement owners who are unwilling to give up the long-term security offered by permanent rights. Equally, however, the environmental flows so obtained are not permanent.

In all of the activity to secure and manage environmental flows, particularly in the Murray-Darling Basin, it is apparent that coordination is lacking. The National Water Commission (2007) has explicitly recognised this in its first biennial assessment of the National Water Initiative: "The multiplicity of programs and mechanisms for recovering water for the environment is potentially inefficient". 12

Despite this, it is clear that governments have recognised and made some response to social demands for environmental flows, even if their actions have not been adequately informed by quantitative assessments such as the one detailed in the previous section of this paper. Weisbrod (1977) has argued that governments will supply public goods such as environmental flows up to the level demanded by the median voter. A potential complication arising in the case of environmental flows, especially in the Murray-Darling Basin, is that the multiple State Governments involved as well as the Commonwealth Government are each seeking to satisfy voters in their individual constituencies, potentially ignoring the consequences of their decisions for voters elsewhere. For instance, given that environmental flows purchased by the Victorian Government to meet their median voter's requirements will help satisfy NSW residents and SA residents-all of whom are citizens of the Commonwealtl-and that their governments are also purchasing water for the environment, there may eventually be an oversupply of environmental water. This is contrary to the familiar free-riding hypothesis that suggests each government would hold back supplying environmental flows in the hope that another government would step into the breach. However, the benefit enjoyed by the supplying government is not measured in terms of improved environmental condition. That will only be achieved in the longer term. What governments are aiming for is political recognition of their efforts to protect river health. Governments in other jurisdictions cannot provide that recognition and so free riding is not an option.

There is a vested interest on the part of all govermments to coordinate their purchases to avoid inefficiencies of this nature. Measures taken by the Commonwealth

12 htı://www.nwe.gov.au/nwi/hiemaial_assessment/hest_practice_pricing.cim. 


\section{JEFF BENNETT}

Government under the Water Act of 2007 to take over control of water in the Murray Darling Basin may help to address this issue.

The on-going success of the private sector non-profit interests in this setting remains contentious. Certainly, if governments do not coordinate across each others' actions the publicly supplied environmental flows may be extended beyond that demanded by the median voter in each jurisdiction. In such a setting, it is doubtful whether entities like the NCWT will be able to raise significant amounts of money to secure volumes of water that will be effective in providing additional environmental values. Weisbrod's (1977) logic suggests that the heterogeneity of a population must be sufficiently large that some elements within society with greater than median voter demands are both large enough and homogeneous enough to see private, not-for-profit suppliers of public goods emerge. With public sector supplies of environmental water extending beyond the median voter's demand, the chances of special interest groups having sufficiently strong demands to generate successful private not-for-profit supply would be reduced.

\section{Conclusions}

Water is a highly contentious issue in the Australian community. The resource use conflict between extractive uses and environmental flows has developed at a time when record-breaking droughts have been experienced, highlighting the issue, even for urban dwellers. The rush to satisfy voter discontent with the environmental consequences of previous water management practices has led to a confusing array of policy initiatives, which are in danger of delivering sub-optimal outcomes.

This paper has aimed to clarify matters by demonstrating the capacity of Choice Modelling to provide policy makers with information on the relative magnitude of the marginal values that are generated for society by the re-allocation of water entitlements to environmental flows. This information is useful in considering just where to draw the line between environmental and extractive uses.

The paper also provides clarification on the issue of managing environmental flows. The danger exposed is one of a lack of coordination across the various entities that have been formed to enter water markets to secure environmental water. While the private sector not-for-profits face the discipline of the market in raising funds to be used for purchases, government entities do not. In their individual efforts to satisfy voters' demands, State and Federal governments may act in an uncoordinated manner that will lead to an oversupply of environmental flows.

\section{REFERENCES}

Adamowicz, W. (2004) "What's it Worth? An Examination of Historical Trends and Future Directions in Environmental Valuation", Australian Journal of Agricultural and Resource Economics 48, pp. 419-443.

Bennett, J.W. and R. K. Blamey (2001) The Choice Modelling Approach to Environmental Valuation (Cheltenham: Edward Elgar Publishing).

Rolfe, J. and J. Bennett (2006) Choice Modelling and the Transfer of Environmental Values (Cheltenham: Edward Elgar Publishing).

Scarborough, B. and H Lund (2007) Saving our Streams: Harnessing Water Markets (Bozeman: Property and Environment Research Centre). 


\section{DEFINING AND MANAGING ENVIRONMENTAL FLOWS}

van Bueren, M. and J. Bennett (2004) "Towards the Development of a Transferable Set of Value Estimates for Environmental Attributes", Australian Journal of Agricultural and Resource Economics, 48, pp. I-32.

Victorian Environmental Assessment Council (2006), River Red Gum Forests Investigation: Discussion Paper (Melbourne: Victorian Environmental Assessment Council).

Wesibrod, B. A. (1977) The Voluntary Nonprofit Sector (Lexington: Lexington Books). 